\title{
IN SILICO APPROACH OF COLLAGEN FROM TUNA FISH BY-PRODUCT AS ANGIOTENSIN-CONVERTING ENZYME INHIBITOR
}

\author{
ANDRIATI NINGRUM ${ }^{1 *}$, HELI SITI HALIMATUL MUNAWAROH ${ }^{2}$
}

${ }^{1}$ Department of Food Science and Agricultural Product Technology, Faculty of Agricultural Technology, Gadjah Mada University, Yogyakarta 55281, Indonesia. ${ }^{2}$ Department of Chemistry, Faculty of Mathematics and Science, Indonesia University of Education, Bandung 40522 Indonesia. Email: andriati_ningrum@ugm.ac.id

Received: 08 July 2019, Revised and Accepted: 02 August 2019

ABSTRACT

Objective: This study explores the sustainable valorization of by-products from tuna fish based on in silico approach.

Methods: In silico approaches (BIOPEP database, PeptideRanker database, peptide calculator [PepCalc] database, and toxin prediction [ToxinPred] database) were employed to evaluate the potential of collagens from tuna as a potential source of bioactive peptides. Furthermore, primary structure, biological potential, physicochemical, sensory, and toxicity characteristics of the theoretically released angiotensin-converting enzyme (ACE) inhibitor collagen peptides were predicted.

Results: Tuna collagen was selected as a potential precursor of bioactive peptides based on in silico analysis. Most notable among these are ACE inhibitory peptides. First, the potential of tuna collagen for the releasing bioactive peptides was evaluated by determining the frequency of occurrence of fragments with a given activity. Through the BIOPEP database analysis, there are many bioactive peptides in tuna collagen sequences. Then, an in silico proteolysis using selected enzymes (papain and pepsin) to obtained ACE inhibitory peptides was investigated and then analyzed using PeptideRanker and PepCalc. Cytotoxicity analysis using the online toxic prediction tool ToxinPred revealed that all in silico proteolysis-derived ACE inhibitory peptides are non-cytotoxic.

Conclusions: Overall, the present study highlights that the tuna collagens could be a promising precursor of bioactive peptides that have an antihypertensive effect (ACE inhibitory activities) for developing functional food or nutraceutical products.

Keywords: In silico, Valorization, Tuna, By-product, Angiotensin-converting enzyme inhibitor.

(C) 2019 The Authors. Published by Innovare Academic Sciences Pvt Ltd. This is an open access article under the CC BY license (http://creativecommons. org/licenses/by/4. 0/) DOI: http://dx.doi.org/10.22159/ajpcr.2019.v12i10.34816

\section{INTRODUCTION}

Fish skin gelatin is extensively employed as an ingredient to improve the elasticity, consistency, and stability of foods, but it can also be a source of collagen. Collagen has a triple helical molecule that contains three polypeptide $\alpha$-chains that are coiled around each other and composed of (Glycine-X-Y)n, where $X$ and $Y$ are often proline and hydroxyproline (Hyp), respectively. At present, 29 different collagen types (type I-XXIX) have been identified. Type I is the most common form of collagen in the vertebrate connective tissues [1].

Nowadays, collagen and its derivatives have potential commercial value for a broad application range of pharmaceutical, cosmetic, food, and biomedical industry applications [1,2]. The skin and bone of land-based animals (bovine and porcine) have been the conventional sources of collagen $[2,3]$. Unfortunately, the use of bovine and porcine collagens has raised serious problems regarding consumers' health $[2,3]$. Therefore, there is a strong necessity nowadays to find the alternative sources of collagen. Aquatic species and their processing by-products have been recognized as potential alternative sources, owing to their availability, lack of disease risk, lack of dietary restriction, and high collagen yields. Incorporation of collagen-derived bioactive compounds can be an innovative approach to the production of functional food and nutraceutical products with potential health-promoting properties $[1,4]$.

Marine-derived bioactive peptides from collagen are recently emerging nutraceutical field as supplements in health functional food formulations due to their diverse health-promoting benefits $[1,3,5]$. Interestingly, bioactive peptides are able to inhibit the ACE, involved in the regulation of human blood pressure and fluid homeostasis via the renin-angiotensin system. In fact, the ACE is responsible to convert the angiotensin I into angiotensin II that constricts the arteries and, as a consequence, increases the blood pressure [6,7]. Further, it is involved in the inactivation of the bradykinin, which is a known vasodilator [8].

Screening for ACE-I inhibitors from novel substrates using conventional methods is an expensive and time-consuming process. It involves using previously reported studies to select proteases that demonstrate the highest potential to liberate ACE-I inhibitory peptides and further experimentally testing each one of them for their in vitro activity. The process can be simplified using in silico analysis and tools such as BIOPEP (http://www.uwm.edu.pl/biochemia/index.php/pl/biopep) and Expssy Peptide Cutter (http://web.expasy.org/peptide_cutter/). These tools allow for the theoretical prediction of the potential of various substrates with known protein sequences to generate bioactive peptides, using enzymes with known cleavage specificities [9]. As well, this work aims to investigate the tuna collagens that could be a promising precursor of bioactive peptides that have an antihypertensive effect (ACE inhibitory activities) for developing functional food or nutraceutical products.

\section{METHODS}

Profiles of the potential biological activity of tuna collagen The assessment of the biological potential of tuna collagen was carried out using the BIOPEP analysis (http://www.uwm.edu.pl/biochemia/ index.php/en/biopep). The collagen type I protein sequences obtained from the NCBI database were analyzed for the profiles of potential biological activity. The potential of type I fish collagen-derived ACE inhibitor peptide sequences was also screened. In addition, a frequency of the occurrence of bioactive fragments in the type I collagen chains was 
also calculated. Furthermore, collagen type I-1 protein sequences were also subjected to in silico proteolysis to predict the theoretical peptide sequences cleaved by enzyme mixture (pepsin + papain) [1]. Finally, a list of potential ACE peptides was generated for further analysis.

\section{Peptide ranking}

The potential of the fish collagen-derived ACE inhibitor peptides was predicted using PeptideRanker (http://bioware.ucd.ie/compass/ biowareweb/) tool. The PeptideRanker tool was used to calculate the peptide score of the selected fish collagen-derived ACE inhibitor peptides. PeptideRanker gave the peptide score in the range of $0-1$. The maximum score [1] showed the most active peptides, and on the other hand, the least score (0) showed the least active peptides.

\section{Sensory characteristic prediction}

Peptides and amino acids are belonging to compounds that have the capacity to altering the taste of food commodities. The occurrence frequency of sensory characteristics in the hydrolyze collagen $\alpha$-chains was predicted using the BIOPEP analysis. The occurrence frequencies of the various sensory characteristics were also predicted for the hydrolyzing $\alpha$-chains of the collagen using papain, pepsin, and their mixtures. Furthermore, the sensory characteristics of the selected collagen-derived ACE inhibitor peptides were also predicted.

\section{The physicochemical characteristics of the collagen derived}

The potential ACE inhibitor peptides were evaluated using online peptide calculators. The theoretical molecular weight, isoelectric point, the peptide charge at $\mathrm{pH} \mathrm{7,} \mathrm{estimated} \mathrm{solubility,} \mathrm{and} \mathrm{extinction}$ coefficient of the screened antioxidative collagen peptides were estimated with the online PepCalc software (http://pepcalc.com/).

\section{Toxicity prediction}

The toxicity of the peptides is one of the major concerns toward the development of collagen-based functional food ingredients. Therefore, the in silico toxicity prediction of the identified collagen-derived ACE inhibitor peptides was investigated using ToxinPred (http://www. imtech.res.in/raghava/toxinpred/index.html).

\section{RESULTS AND DISCUSSION}

\section{Profile of potential biological activity}

The several potential biological activities of both collagen chains were reported in Table 1 . Hence, the time-saving and more economical computer-simulated method or in silico methods can be used to predict the generation of the bioactive collagen peptides. The biological activities of the collagen type I-1 were evaluated using the BIOPEP

Table 1: Profile of biological activity of collagen type 1 from tuna fish

\begin{tabular}{lll}
\hline No. & Activity & Frequency (A) \\
\hline 1. & ACE inhibitor & 0.7458 \\
2. & Activating ubiquitin-mediated proteolysis & 0.0026 \\
3. & Alpha-glucosidase inhibitor & 0.0013 \\
4. & Anorectic & 0.0222 \\
5. & Antiamnestic & 0.1636 \\
6. & Antioxidative & 0.0411 \\
7. & Antithrombotic & 0.1799 \\
8. & Bacterial permease ligand & 0.0013 \\
9. & Chemotactic & 0.0235 \\
10. & Dipeptidyl peptidase IV inhibitor & 0.7555 \\
11. & Embryotoxic & 0.0007 \\
12. & Hypotensive & 0.0072 \\
13. & Immunomodulating & 0.0007 \\
14. & Immunostimulating & 0.0007 \\
15. & Inhibitor & 0.0130 \\
16. & Neuropeptide & 0.0072 \\
17. & Opioid & 0.0007 \\
18. & Regulating & 0.1643 \\
19. & Stimulating & 0.0111 \\
\hline
\end{tabular}

ACE: Angiotensin-converting enzyme analysis tool. It was predicted by the tool that collagen has several potential biological activities (Table 1).

The predicted major potential biological activities of the collagen were ACE inhibitory activity and dipeptidyl peptidase IV inhibitory activity. The frequency of the ACE inhibitory and dipeptidyl peptidase IV inhibitory activity in the collagen I-1 was approximately 0.7458 and 0.7555 , respectively. In addition, the frequency of the antioxidative peptides in collagen type I was 0.0411 . The results of this study are in agreement with the report previously who reported the fish collagen peptides to have the various potential biological activities. The previous study of tuna frame collagen hydrolysate also has been investigated to have ACE inhibitor activity based on in vitro assay. From the result of the study, it is suggested that the ACE inhibitory peptide from tuna frame protein hydrolysate could be potential candidates to develop nutraceuticals and pharmaceuticals against hypertension and its related disease. In addition, it is expected that this study will contribute to developing an interest in basic research and potential application of bioactive peptides [10].

The biological activities of peptides isolated from marine collagen and also gelatin have been reported in different studies. In most studies in the field of food science and technology, the focus has been on antioxidant and antihypertensive/ACE inhibitory activities. The antioxidant activities of bioactive peptides are mainly due to the presence of some aromatic amino acids and histidine. Gelatin peptides are rich in hydrophobic amino acids which result in higher emulsifying ability and, marine gelatin peptides possess higher antioxidant effects than peptides derived from other sources [11].

Furthermore, collagen and also gelatin-derived peptides represent numerous other bioactivities such as antimicrobial activity, mineralbinding capacity, lipid-lowering effect, immunomodulatory activity, and beneficial effects on the skin, bone, or joint health. Due to the dominant presence of hydrophobic amino acids in gelatin, it exhibits high emulsifying ability for hydrophilic-hydrophobic partitioning. Furthermore, specific amino acid arrangements such as Gly, Pro, and Hyp merit special consideration, as the content of Pro is able to scavenge free radicals [12].

\section{In silico proteolysis}

The potential fish collagen type I-derived peptide sequences displaying the ACE inhibitor were predicted using the BIOPEP analysis tool. The lists of the theoretically released ACE inhibitor peptide from tuna collagen are summarized in Table 2 . The tuna collagen- 1 and protein sequences were also subjected to in silico proteolysis using the BIOPEP tool. The supposed ACE inhibitory peptide derived from the hydrolysis of tuna collagen- 1 and by pepsin and papain proteases is summarized and presented (Table 2). Previously yet researched showed the mix of pepsin and also papain can generate several bioactive peptides [1]. Hence, we also try to use these two enzymes to screen several bioactive peptides that can act as an ACE inhibitor.

Based on Table 2, mostly peptides released by hydrolysis using papain and pepsin are dipeptides. This result aligned with the previous research using these two different enzymes but different raw materials which are carp collagens [1]. All of the ACE inhibitor peptides generated from the mixture of the enzymes were dipeptides with ACE inhibitor activity, as predicted by BIOPEP tool. The pepsin and papain mixture or alone could be able to generate several ACE inhibitor dipeptides. This fact suggests that these enzymes could not be able to hydrolyze the tuna collagen effectively for releasing the numerous ACE inhibitor peptide sequences. Therefore, the specific enzyme such as collagenase may be able to cleave the type I collagen at the various sites for the generation of the ACE inhibitor peptides [1].

\section{Peptide ranking of ACE inhibitor collagen peptides}

The identified ACE inhibitor collagen-derived peptide profile was subjected to activity prediction by in silico methods. The potential of the ACE inhibitor peptides has been calculated using PeptideRanker. PeptideRanker server can rank the peptide sets according to 
Table 2: In silico assay using pepsin and papain release peptides with ACE inhibitor from tuna collagen as precursor

\begin{tabular}{|c|c|c|c|c|c|c|c|}
\hline $\begin{array}{l}\text { Peptide } \\
\text { ID }\end{array}$ & Sequence & Location & Name & Function & Activity & $\begin{array}{l}\text { Monoisotopic } \\
\text { mass }\end{array}$ & $\begin{array}{l}\text { Chemical } \\
\text { mass }\end{array}$ \\
\hline 3537 & PR & $(178-179)$ & ACE inhibitor & $\begin{array}{l}\text { Inhibitor of ACE (EC 3.4.15.1) } \\
\text { (MEROPS ID: XM02-001) }\end{array}$ & ACE inhibitor & 271.1530 & 271.3050 \\
\hline 3751 & KK & $(1411-1412)$ & & & $\begin{array}{l}\text { Bacterial } \\
\text { permease ligand }\end{array}$ & 274.1880 & 274.3480 \\
\hline 7513 & PL & $(909-910)$ & $\begin{array}{l}\text { ACE inhibitor from } \\
\text { Alaska pollock fish skin }\end{array}$ & $\begin{array}{l}\text { Inhibitor of ACE (EC 3.4.15.1) } \\
\text { (MEROPS ID: XM02-001) }\end{array}$ & ACE inhibitor & 228.1360 & 228.2770 \\
\hline 7586 & KR & $(468-469)$ & ACE inhibitor & & ACE inhibitor & 302.1950 & 302.3620 \\
\hline 7594 & VG & $(895-896)$ & ACE inhibitor & $\begin{array}{l}\text { Inhibitor of ACE (EC 3.4.15.1) } \\
\text { (MEROPS ID: XM02-001) }\end{array}$ & ACE inhibitor & 174.0890 & 174.1850 \\
\hline 7595 & IG & $(460-461)$ & ACE inhibitor & $\begin{array}{l}\text { Inhibitor of ACE (EC 3.4.15.1) } \\
\text { (MEROPS ID: XM02-001) }\end{array}$ & ACE inhibitor & 188.1050 & 188.2120 \\
\hline 7600 & $\mathrm{AG}$ & $(229-230)$ & ACE inhibitor & $\begin{array}{l}\text { Inhibitor of ACE (EC 3.4.15.1) } \\
\text { (MEROPS ID: XM02-001) }\end{array}$ & ACE inhibitor & 146.0580 & 146.1310 \\
\hline 7613 & WG & $(1450-1451)$ & ACE inhibitor & $\begin{array}{l}\text { Inhibitor of ACE (EC 3.4.15.1) } \\
\text { (MEROPS ID: M02-001) }\end{array}$ & ACE inhibitor & 261.1000 & 261.2650 \\
\hline 7617 & QG & $(23-24)$ & ACE inhibitor & & ACE inhibitor & 203.0790 & 203.1830 \\
\hline 7618 & SG & $(265-266)$ & ACE inhibitor & & ACE inhibitor & 162.0530 & 162.1320 \\
\hline 7622 & EG & $(36-37)$ & ACE inhibitor & $\begin{array}{l}\text { Inhibitor of ACE (EC 3.4.15.1) } \\
\text { (MEROPS ID: XM02-001) }\end{array}$ & ACE inhibitor & 204.0630 & 204.1680 \\
\hline 7624 & NG & $(1191-1192)$ & ACE inhibitor & & ACE inhibitor & 189.0639 & 189.1560 \\
\hline 7625 & $P G$ & $(135-136)$ & ACE inhibitor & $\begin{array}{l}\text { Inhibitor of ACE (EC 3.4.15.1) } \\
\text { (MEROPS ID: M02-001) }\end{array}$ & ACE inhibitor & 172.0730 & 172.1690 \\
\hline 7628 & VR & $(20-21)$ & $\begin{array}{l}\text { ACE inhibitor from } \\
\text { k-Casein (fr. 67-68) }\end{array}$ & $\begin{array}{l}\text { Inhibitor of ACE (EC 3.4.15.1) } \\
\text { (MEROPS ID: XM02-001) }\end{array}$ & ACE inhibitor & 273.1690 & 273.3210 \\
\hline 7681 & DG & $(94-95)$ & ACE inhibitor from soy & $\begin{array}{l}\text { Inhibitor of ACE (EC 3.4.15.1) } \\
\text { (MEROPS ID: XM02-001) }\end{array}$ & ACE inhibitor & 190.0479 & 190.1410 \\
\hline 7683 & NF & $(151-152)$ & ACE inhibitor from garlic & & ACE inhibitor & 279.1109 & 279.2810 \\
\hline 7685 & $\mathrm{SF}$ & $(3-4)$ & $\begin{array}{l}\text { ACE inhibitor from } \\
\text { garlic }\end{array}$ & $\begin{array}{l}\text { Inhibitor of ACE (EC 3.4.15.1) } \\
\text { (MEROPS ID: M02-001) }\end{array}$ & ACE inhibitor & 252.1000 & 252.2570 \\
\hline 7833 & PT & $(572-573)$ & ACE inhibitor & & ACE inhibitor & 216.0990 & 216.2220 \\
\hline
\end{tabular}

ACE: Angiotensin-converting enzyme

structure-function patterns [13]. The peptide generated from the pepsin hydrolysis showed the maximum peptide ranking scores. The ACE inhibitor dipeptide PR and KK showed the maximum peptide rank score of 0.99 and 0.94 , respectively (Table 3). Papain and pepsin were generated as the most active ACE inhibitor peptides $[2,14]$.

Sensory characteristic profile of tuna collagens hydrolysates and peptides

As we know that the sensory characteristics of the potential ACE inhibitor peptides were also evaluated (Table 3). Taste is the major factor that makes organisms to choose what to ingest and also protects from ingesting toxic compounds. Taste is the key factor responsible for the determination of any food commodity quality.

Humans recognize five basic taste sensations (bitter, salty, sour, sweet, and umami). The taste of foods is affected by some molecules with specific chemical nature such as peptides derived from food proteins. In this study, it was predicted that all of the ACE inhibitor peptides have a bitter taste. In addition, the collagen hydrolysate prepared from the hydrolysis of the papain and pepsin was also subjected to the prediction of overall sensory characteristics. The sensory characteristic occurrence frequency was also predicted in the hydrolyze collagen chains. In silico conditions, it was observed that the occurrence frequency of sweet characteristics in collagen chains hydrolysate is lower as compared to the bitter hydrolysate (Table 3). Therefore, this study provided theoretical feasibility for application of in silico analysis to predict and release of the ACE inhibitory peptides from tuna collagen.
Table 3: Peptide ranker and sensory evaluation and toxicity prediction of peptides from collagen precursor as ACE inhibitor

\begin{tabular}{llll}
\hline No. & Peptide & Peptide rank score & Sensory evaluation \\
\hline 1. & PR & 0.992384 & Bitter \\
2. & KK & 0.948796 & Bitter \\
3. & PL & 0.941145 & Bitter \\
4. & VK & 0.877086 & Bitter \\
5. & KR & 0.811148 & Bitter \\
6. & VG & 0.787626 & Umami \\
7. & IG & 0.546994 & Bitter \\
8. & AG & 0.501816 & Sweet \\
9. & KG & 0.407386 & Umami \\
10. & WG & 0.394584 & Bitter \\
11. & QG & 0.391148 & Sweet \\
12. & SG & 0.387797 & Sweet \\
13. & EG & 0.38751 & Sweet \\
14. & NG & 0.312686 & Bitter \\
15. & PG & 0.249461 & Bitter \\
16. & VR & 0.213072 & Salt \\
17. & DG & 0.168013 & Umami \\
18. & NF & 0.114691 & Bitter \\
19. & SF & 0.100261 & Bitter \\
20. & AR & 0.0591457 & Salty \\
21. & PT & 0.03329 & Bitter \\
\hline
\end{tabular}

ACE: Angiotensin-converting enzyme

Physicochemical characteristics of collagen peptides

The identified ACE inhibitor collagen-derived peptides were subjected to predict the various physicochemical characteristics and primary 
Table 4: Toxicity prediction of peptides from collagen precursor as ACE inhibitor

\begin{tabular}{|c|c|c|c|c|c|c|c|c|}
\hline No. & $\begin{array}{l}\text { Peptide } \\
\text { sequence }\end{array}$ & Support vector machine score & Prediction & Hydrophobicity & Hydropathicity & Hydrophilicity & Charge & Mol. wt. \\
\hline 1. & PR & -0.8 & Non-toxin & -0.92 & -3.05 & 1.5 & 1 & 271.33 \\
\hline 2. & KK & -1 & Non-toxin & -1.1 & -3.9 & 3 & 2 & 274.38 \\
\hline 3. & PL & -0.8 & Non-toxin & 0.23 & 1.1 & -0.9 & 0 & 228.31 \\
\hline 4. & VK & -0.8 & Non-toxin & -0.28 & 0.15 & 0.75 & 1 & 245.34 \\
\hline 5. & $\mathrm{KR}$ & -0.8 & Non-toxin & -1.43 & -4.2 & 3 & 2 & 302.39 \\
\hline 6. & VG & -0.8 & Non-toxin & 0.35 & 1.9 & -0.75 & 0 & 174.22 \\
\hline 8. & AG & -0.8 & Non-toxin & 0.21 & 0.7 & -0.25 & 0 & 146.16 \\
\hline 9. & KG & -0.8 & Non-toxin & -0.47 & -2.15 & 1.5 & 1 & 203.26 \\
\hline 10. & WG & -0.8 & Non-toxin & 0.27 & -0.65 & -1.7 & 0 & 261.3 \\
\hline 11. & $\mathrm{QG}$ & -0.8 & Non-toxin & -0.26 & -1.95 & 0.1 & 0 & 203.22 \\
\hline 12. & SG & -0.79 & Non-toxin & -0.05 & -0.6 & 0.15 & 0 & 162.16 \\
\hline 13. & EG & -0.8 & Non-toxin & -0.23 & -1.95 & 1.5 & -1 & 204.2 \\
\hline 14. & NG & -0.79 & Non-toxin & -0.24 & -1.95 & 0.1 & 0 & 189.19 \\
\hline 15. & $P G$ & -0.8 & Non-toxin & 0.04 & -1 & 0 & 0 & 172.2 \\
\hline 17. & DG & -0.8 & Non-toxin & -0.28 & -1.95 & 1.5 & -1 & 190.17 \\
\hline 18. & NF & -0.8 & Non-toxin & -0.02 & -0.35 & -1.15 & 0 & 279.31 \\
\hline 19. & SF & -0.8 & Non-toxin & 0.17 & 1 & -1.1 & 0 & 252.28 \\
\hline 20. & $\mathrm{AR}$ & -0.8 & Non-toxin & -0.76 & -1.35 & 1.25 & 1 & 245.29 \\
\hline 21. & PT & -0.8 & Non-toxin & -0.12 & -1.15 & -0.2 & 0 & 216.25 \\
\hline
\end{tabular}

*Mol. wt.: Molecular weight. ACE: Angiotensin-converting enzyme

structure (http://pepcalc.com/). The result of this study indicates that most of the ACE inhibitor peptides have low-molecular-weight profile (Table 4). The isoelectric point of the predicted ACE inhibitor collagen peptides was found at the range of $0.68-11.39 \mathrm{pH}$. Most of the collagenderived ACE inhibitor peptides showed that most of them are good water solubility (Table 4).

\section{Toxicity prediction of collagen-derived ACE inhibitor peptides}

Toxicity of the ACE inhibitor peptides from the tuna collagen type I chains may hamper the development of bioactive peptides in the food industry. Valine, threonine, arginine, glutamine, methionine, leucine, lysine, isoleucine, phenylalanine, and alanine are primary components of the non-toxic peptides, while Pro, histidine, cysteine, and asparagine amino acid residues are predominant in toxic peptides. In the present study, tuna collagenderived ACE inhibitor peptides majority do not contain the amino acid residues that are present in the toxic peptides. It was predicted from the ToxinPred analysis that all in silico-derived tuna collagen ACE inhibitor peptides most of them are non-toxic (Support Vector Machine scores $<0$ ) (Table 4). Therefore, these peptides can be used as potential functional ingredients.

\section{CONCLUSIONS}

Using in silico approach, we can conclude that several bioactive peptides that have ACE inhibitory activity can be derived from collagen. The present study highlighted that in silico digestions of tuna collagen chains using papain and pepsin effectively generated the ACE inhibitor activities that can provide a basis for the development of tuna collagen as a precursor of antihypertensive peptides in the food industries. Therefore, the utilization of fish processing by-products for the extraction of collagen and the application concept of valorization can be assessed as a waste management approach.

\section{ACKNOWLEDGMENT}

The authors gratefully acknowledge the Toray Science Foundation, Japan, for supporting this research.

\section{AUTHOR CONTRIBUTION}

AN: Design in silico analysis research, performed in silico experiment and preparation manuscript. HSHM: Design in silico analysis research, performed in silico experiment

\section{CONFLICT OF INTEREST}

The authors declare that we have no conflict of interests. The author wishes to thank the Toray Science Foundation for supporting this research. The funder had no role in study design, data collection, and analysis, decision to publish, or preparation of the manuscript.

\section{REFERENCES}

1. Pal GK, Suresh PV. Physico-chemical characteristics and fibrilforming capacity of carp swim bladder collagens and exploration of their potential bioactive peptides by in silico approaches. Int J Biol Macromol 2017;101:304-13.

2. Fu Y, Young JF, Løkke MM, Lametsch R, Aluko RE, Therkildsen M. Revalorisation of bovine collagen as a potential precursor of angiotensin I-converting enzyme [ACE] inhibitory peptides based on in silico and in vitro protein digestions. J Funct Foods 2016;24:196-206.

3. Mine Y, Li-Chan E, Jiang B. Bioactive Proteins and Peptides as Functional Foods and Nutraceuticals. Hoboken, New Jersey: John Wiley and Sons; 2010.

4. Lacroix IM, Li-Chan EC. Evaluation of the potential of dietary proteins as precursors of dipeptidyl peptidase [DPP]-IV inhibitors by an in silico approach. J Funct Foods 2012;4:403-22.

5. Gu Y, Majumder K, Wu J. QSAR-aided in silico approach in evaluation of food proteins as precursors of ACE inhibitory peptides. Food Res Int 2011;44:2465-74.

6. Ranjini HS, Pue G, Kamath SU, Setty M, Hadapad B, Kamath A. An in vitro Study of Cinnamomum zeylanicum as natural inhibitor of angiotengsin-converting enzyme [ACE] on sheep [ovis aries] tissues. Asian J Pharm Clin Res 2016;9:9-12.

7. Mun'im AM, Munadhil MA, Puspitasari N, Yanuar A. Angiotensin converting enzyme inhibitory activity of melinjo [Gnetum gnemon L.] seed extracts and molecular docking of its stilbene constituets. Asian J Pharm Clin Res 2017;10:243-8.

8. Abdelhedi O, Nasri R, Jridi M, Mora L, Oseguera-Toledo ME, Aristoy MC, et al. In silico analysis and antihypertensive effect of ACEinhibitory peptides from smooth-hound viscera protein hydrolysate: Enzyme-peptide interaction study using molecular docking simulation. Process Biochem 2017;58:145-59.

9. Gangopadhyay N, Wynne K, O'Connor P, Gallagher E, Brunton NP, Rai DK, et al. In silico and in vitro analyses of the angiotensin-I converting enzyme inhibitory activity of hydrolysates generated from crude barley (Hordeum vulgare) protein concentrates. Food Chem 2016;203:367-74.

10. Lee S, Qian Z, Kim S. A novel angiotensin I converting enzyme inhibitory peptide from tuna frame protein hydrolysate and its antihypertensive effect in spontaneously hypertensive rats. Food Chem 2010;118:96-102. 
11. Atef M, Ojagh SM. Health benefits and food applications of bioactive compounds from fish byproducts : A review. J Funct Foods 2017;35:673-81

12. Karayannakidis PD, Zotos A. Fish processing by-products as a potential source of gelatin. A review fish processing by-products as a potential source of gelatin : A review. J Aquat Food Prod Technol 2016;25:65-92.
13. Garg S, Apostolopoulos V, Nurgali K, Mishra VK. Evaluation of in silico approach for prediction of presence of opioid peptides in wheat. J Funct Foods 2018;41:34-40.

14. Lo WM, Li-Chan EC. Angiotensin I converting enzyme inhibitory peptides from in vitro pepsin-pancreatin digestion of soy protein. J Agric Food Chem 2005;53:3369-76. 